\section{Commentary: Beware of the esophagus - it's never too late for a complication}

\author{
Stephanie H. Chang, MD
}

Esophagectomy is a high-risk procedure with a significant risk of short-term and long-term morbidity. ${ }^{1}$ The most common long-term complications include dysphagia, reflux, delayed gastric emptying, ${ }^{2}$ and anastomotic strictures, whereas hiatal hernias are a rare complication occurring in $<1 \%$ of patients after esophagectomy. ${ }^{3}$ Patients with paraconduit hernias can be asymptomatic or present with cough, chest pain, dysphagia, or obstructive signs (ie, nausea, vomiting). For symptomatic patients, surgical repair is indicated. The median time to diagnosis of symptomatic paraconduit hernias was 21 months in one singlecenter study. ${ }^{2}$

In this case report, Watkins and colleagues ${ }^{4}$ report the case of a 65-year-old female patient who had a late complication of a diaphragmatic hernia resulting in fecopneumothorax. Four years after neoadjuvant chemoradiation and minimally invasive esophagectomy, she developed left shoulder pain, with a normal chest radiograph. She was discharged from the emergency department but represented days later with respiratory distress and a fecopneumothorax. A computed tomography (CT) scan of the chest showed a diaphragmatic defect with colon, consistent with the strangulated colon that was seen in the operating room. This segment of colon was resected, and the diaphragmatic defect was repaired. This hernia was likely

From the Department of Cardiothoracic Surgery, New York University Langone Health, New York, NY.

Disclosures: The author reported no conflicts of interest.

The Journal policy requires editors and reviewers to disclose conflicts of interest and to decline handling or reviewing manuscripts for which they may have a conflict of interest. The editors and reviewers of this article have no conflicts of interest.

Received for publication Nov 21, 2021; revisions received Nov 21, 2021; accepted for publication Dec 4, 2021; available ahead of print Jan 12, 2022.

Address for reprints: Stephanie H. Chang, MD, Division of Thoracic Surgery, Department of Cardiothoracic Surgery, New York University Langone Health, 530 First

Ave, Suite 9V, New York, NY 10016 (E-mail: stephanie.chang@nyulangone.org). JTCVS Techniques 2022;11:94-5

2666-2507

Copyright (C) 2022 The Author(s). Published by Elsevier Inc. on behalf of The American Association for Thoracic Surgery. This is an open access article under the CC BY-NC-ND license (http://creativecommons.org/licenses/by-nc-nd/4.0/).

https://doi.org/10.1016/j.xjtc.2021.12.003

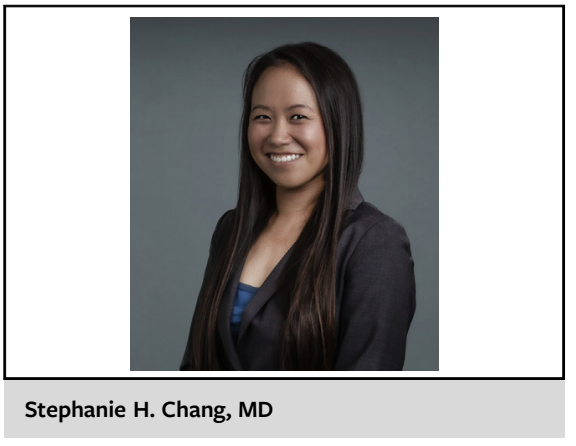

CENTRAL MESSAGE

For patients with an esophagec-

tomy, complications like parae-

sophageal or diaphragmatic

hernias can arise years later. CT

scan remains the gold standard

for diagnosis of these

complications.

secondary to mobilization of the left triangular ligament for a liver wedge resection of a concerning lesion (final pathology was benign) at the time of her initial operation. The authors are to be commended since, despite this unusual complication, she recovered and was discharged home.

This case report describes another possible postesophagectomy complication. If liver mobilization is performed, there is a risk of diaphragmatic injury and subsequent hernias. Delay in diagnosis can result in incarcerated bowel becoming strangulated. As the authors point out, CT scan is the gold standard for diagnosing these rare complications. Even multiple years out, patients with previous esophagectomy who present with chest pain, shortness of breath, or obstructive symptoms should undergo a CT scan to rule out paraconduit or diaphragmatic hernias. Timely diagnosis is essential to preventing further complications, such as strangulation, perforated bowel, or even fecopneumothorax.

\section{References}

1. Wright CD, Kucharczuk JC, O'Brien SM, Grab JD, Allen MS. Predictors of major morbidity and mortality after esophagectomy for esophageal cancer: a Society of Thoracic Surgeons General Thoracic Surgery database risk adjustment model. J Thorac Cardiovasc Surg. 2009;137:587-96.

2. Rove JY, Krupnick AS, Baciewicz FA, Meyers BF. Gastric conduit revision postesophagectomy: management for a rare complication. J Thorac Cardiovasc Surg. 2017;154:1450-8. 
3. Price TN, Allen MS, Nichols FC III, Cassivi SD, Wigle DA, Shen KR, et al. Hiatal hernia after esophagectomy: analysis of 2,182 esophagectomies from a single institution. Ann Thorac Surg. 2011;92:2041-5.
4. Watkins AA, Kalluri A, Gupta A, Gangadharan SP. Iatrogenic diaphragmatic hernia with fecopneumothorax following minimally invasive esophagectomy and liver resection. J Thorac Cardiovasc Surg Tech. 2022;11:89-91. 